a small dry scab in the neighborhood of the opening into the mastoid antrum. On removing this scab, you will find that it is only the outer layer of a mass of epithelium and dried pus which filis the to antrum, and which by its presence as a foreign body has irritated its mucous lining; this irritation has - set up a discharge which, soaking into the mass, has caused it to swell, and it has become so tightly wedged that the discharge cannot get out, and we have backing up, and the consequent pain and tenderness. Often the situation is complicated by the presence of granulations and small polypi.

Treatment consists in filling the ear with warm water with a little bicarbonate of soda in it, and allowing this to remain in the ear ten or fifteen minutes, to try and soften the mass; pulling the mass out or breaking it in pieces by the straight or curved forceps; syringing the ear with the ordinary and the middle-ear syringe; pulling off with the forceps the polypi and granulation tissue, and repeating these processes several times if necessary. Usually we succeed in removing the mass, thus clearing out the antrum, and setting free the imprisoned discharge, with relief to the symptoms; sometimes we do not, and it becomes necessary to make an opening into the mastoid cells, but it is always well, unless the symptoms are very urgent, to try what can be done by the forceps and syringe before resorting to the operation.

These are the methods of treatment to which I wished to call your attention, and these are the cases in which it is appropriate to employ them. Often it is best to try them in a different order from that in which $\mathrm{I}$ have spoken of them; each case has to be judged by itself, and there can be no hard and fast rule laid down.

Let me briefly recapitulate them. In acute inflammation with imperforate membrana: paracentesis; inflation; and hot or cold applications behind the ear. Acute inflammations, with purulent or muco-purulent discharge, and an inadequate opening in the membrana, and also nipple cases : large incision in the membrana; inflation; syringing through the eustachian tube; hot or cold applications over the mastoid.

Inflammation with purulent discharge, where the external auditory canal is almost closed by swelling, and the downward bulging of its posterior superior wall : frequent and prolonged douching with warm water; free incision into the wall of the canal, enlarging the opening in the membrana as soon as the swelling has subsided sufficiently for us to get at it; leeching behind the auricle; and in the more severe cases, especially if fluctuation be detected, Wilde's incision.

In chronic inflammations, where polypi are present: the snare; and, after their removal, the middleear syringe. For cholesteatomatous masses in the attic and antrum, soaking the ear with a solution of bicarbonate of soda; the middle-ear syringe; the use of the straight or curved forceps.

Many of these forms of treatment require the specially trained hand of the aurist; most of them can be best accomplished by him ; but, on the other hand, some of them can be performed perfectly well by the general practitioner, and if it so happen that he cannot call an aurist in consultation, it is far better, in my opinion, for him to try some of the methods which I have mentioned rather than to feel that. if a patient has pain, tenderness, and swelling behind the ear, there is out one thing to be done, namely, to make an opening into the mastoid cells.

You noticed in the bone specimens Nos. II. and IV. how close the lateral sinus came to the mastoid antrum; by an anomalous position of the sinus it sometimes happens that a person operating exactly according to the rules laid down, as to where the opening into the mastoid cells should be made, can not avoid laying bare the sinus. This, fortunately, does not occur frequently, and usually is not attended by any very great danger when the operation is being performed by one who is accustomed to it, and knows exactly what the possibilities are, but it certainly is not an operation to be undertaken by a general practitioner, unless he is unable to procure the assistance of an aurist, and has tried the other methods which I have endeavored to describe to you, without relieving the symptoms. I have purposely confined myself to those cases where the symptoms are not so severe and alarming as to leave no doubt but that the mastoid cells must be laid open.

\section{OBSERVATIONS ON THE STEADINESS OF THE HAND AND ON STATIC EQUILI. BRIUM.}

BY W. N. BULLARD, M. D., AND E. G. BRACKETT, M. D.

Is the spring of 1886 , in conversation with $\mathrm{Dr}$. H. P. Bowditch, one of us suggested the advisability of some contrivance by means of which the steadiness of the hand could be readily determined. Dr. Bowditch thought well of the matter, and kindly in. vented the instrument used, and had it made at the physiological laboratory of the Harvard Medical School. For this instrument we suggest the name of tremograph.

It consists essentially of a long, light, wooden rod, which runs through a closely fitting brass cylinder so hung in a vertical compass-joint on the top of a firm upright as to permit of movement both vertically and horizontally in all directions. One end of this rod is furnished with a thimble or some other contrivance for holding the finger, while to the other is attached a Pfluiger's pen. Various weights may be attached to the rod at various distances from its point of support, which of course can be varied at will, so as to keep it when unmoved in an absolutely horizontal position. The upright, made of brass, is placed in the centre of a rectangular wooden base, which can be moved backward or forward on a wooden platform with low, grooved sides, into which it fits closely. At one end of this platform is a transverse groove behind which rises a transverse board. This groove serves to hold the glass plate over which the paper for the tracings is stretched, while the board supports it behind (see figure). To the contriv-
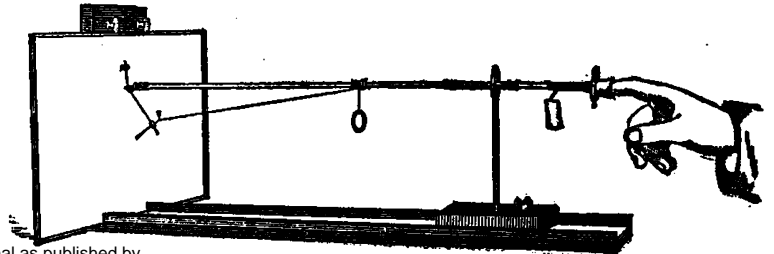
ance holding the pen is attached a string by which the whole can be pulled backwards when not in use, and this string may be fastened to a little hook on the rod. When in use this string is loosened, the penholder hangs vertically, and the pen, projecting horizontally, comes into contact with a sheet of paper, which is placed over a layer of glass so as to offer a surface both sinooth and firm for writing. The finger of the person to be tested is then placed in the thimble, which is connected with the rod by a compass-joint, and the motions of the finger will be accurately recorded on the paper. According as the point of support of the rod is at its mildle or nearer one or the other end, so will the lines on the paper be of the same size as the actual movement or proportionately greater or less. As a matter of fact the tracings were magnified four times, that is, they were to the movements of the hand as four to one.

The first experiments with this instrument were made in the spring of 1886 , but they were too few to be of any positive value. The work was resumed in the winter and spring of 1887, and has been continued more or less steadily ever since.

In order to give our investigations a positive value, it was thought best to first determine what position of the hand was most favorable for the tracing of the tremors or movements to be studied. For this purpose the first series of tracings were made. They were used only to compare the results obtained according as the hand was held in different positions. The tracings in this series were taken from eighty-five patients at the Boston Dispensary, and six tracings were taken from each patient.

It is evident that from such subjects it would be impossible to obtain a normal standard of steadiness; for although all due care was taken not to make use of any whose disease would directly affect them in this regard, yet any person suffering from an ailment severe enough to cause him to seek medical advice could hardly be expected to produce as firm a tracing as in perfect health. Besides, not only did the ordinary nervousness of patients at such a time affect the subjects, but this was greatly increased by their apprehension at the sight of a new and unknown instrument, which was frequently regarded as some modification of the electric battery, and momentarily expected to break out in some startling way.

For this reason it was early determined to use these tracings only to determine the relative value of the different positions of the hand for our purpose. The hand was tested in three positions in every case - pronation, supination, and midway between the two, both with the eyes open and with the eyes closed. This makes six different tests in each case, which for convenience have been numbered in the diagrams as follows :-

$$
\begin{aligned}
& \text { I. Pronation, eyes open. } \\
& \text { II. Promation, ejes closed. } \\
& \text { III. Supination, eycs open. } \\
& \text { IV. Sulination, eyes olosed. } \\
& \text { v. Mirlway, eyes open. } \\
& \text { Vi. Midway, ejes closed. }
\end{aligned}
$$

All the tracings taken have been divided into two groups. I. Stable. II. Mobile.

In a certain proportion of cases no definite direction was taken, but the hand remained approximati ly at the point of starting. The tracing then appeared as an aggregation of many intercrossing lines, and was not developed in any special direction, its size, of course, varying directly with the steadiness of the subject. These cases have been designated as stable. In all the others the hand moved in some general direction from the starting point, and these have been grouped according to the direction taken by the hand (the opposite of that taken by the pen), under the headings Up, Down, Right, and Left. Group I. Stable. 'The hand was held more or less firmly in the original position. It may or may not have been steady, but what movement there was was confined within very narrow limits, and there was no definite continuous movement in any one special direction.

The relative number of tracings of this character obtained under each of the six conditions is represented by the diagrams below. The two series represent respectively the numbers obtained when the right hand of the subject was tested, and when the left hand was used. In each series the height of the lines corresponds more or less roughly with the actual number of tracings in said series, and this number is noted by the Arabic figures, while the Roman numerals below each vertical line denote the special condition under which the tracing was taken.
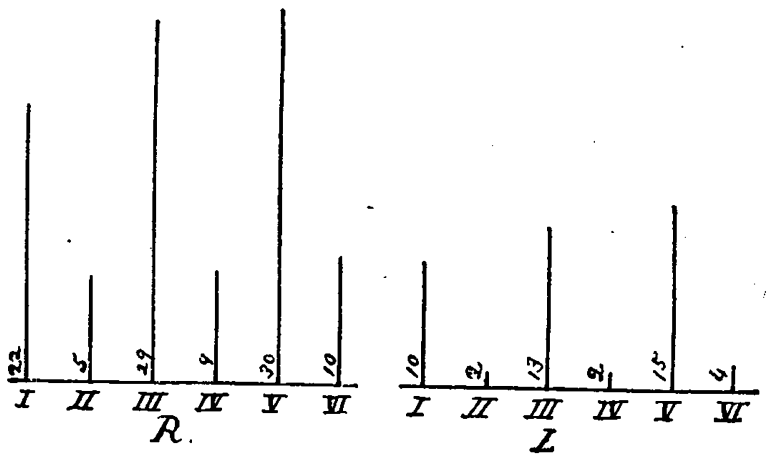

Comparing the lines in each diagram, which represent the number of the tracings in which the subject's eyes were open (Nos. I., III., V.), it is seen that the lines increase in height in the order named, and again, in those representing the number of tracings in which the eyes were closed (Nos. II., IV., VI.), a similar increase in the same order is observed. Thus the number holding the hand approximately in the original place is smallest in the position of pronation, and greatest when the hand is held midway between supination and pronation. Moreover, if we compare the average excursion, in both vertical and horizontal directions, of tracings in this group in which the eyes were open, with those in which the eyes were closed, the hand being held in each case in the same position, we find that the loss of the control of sight is felt more in the position of pronation than in either of the others, except in that of supination with the eyes closed, when the lateral movement predominated.

The following are the figures: -

Right hand. Pronation, eyes open (I.) 22 : eyes closed (II) 5. Supination, eyes open (III.) 29 ; eyes closed (IV.) 9.
Midway, eyes upw (V.) 30 ; eyis closed (VI.) 10.

Left hand.

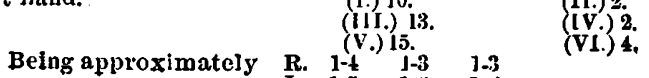


Group II. consists of those tracings in which some decided movement of the lines in some particular direction from the starting point is evident. In these the hand has not been held more or less approximately in the same position, but has moved gradually in one direction or another. This is entirely independent of its general steadiness or tremulousness (shown by the firmness of the line).

In order to obtain the amount of movement of the hand from the starting point in each direction, that is, the total excursion, the lergth and breadth of all the tracings were carefully measured. As before stated, the rod was so arranged that the tracing was in each case four times the size of the actual movement.
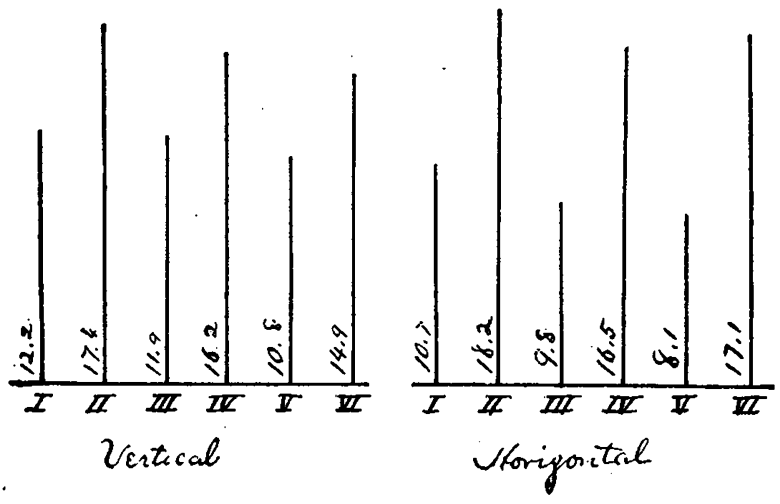

The average excursion in each position for all tracings (Groups I. and II.) is seen in above diagram. The measurements were taken between the extremes in the vertical and horizontal planes. In series I. III. and V., that is, those with eyes open, the height of the lines diminishes in the order named in both planes and with either hand. The same holds good in series II., IV., and VI., where the eyes were closed, except that with the left hand VI. is six mm. longer than IV.; but if we add the averages of both dimensions VI. is less than IV. in all cases.

The average excursion in both planes in millimetres is as follows :-

$\begin{array}{lllllll}\text { Eyes open, } & \text { I. } & \text { II. } & \text { III. } & \text { IV. } & \text { V. } & \text { V1. } \\ \text { Eyes shut, } & & 17.8 & 9.09 & 9.7 & & 10.5\end{array}$

Now, if we compare the relative stability, as thus shown, with that obtained in our previous consideration of Group I., we find it also to be least in pronation. Thus the position of pronation gives the greatest excursion both when all the tracings are considered, and likewise when only those of Group I. are measured.

No attempt has been made to draw any conclusions in regard to direction in these tracings, as the second series was much more valuable for that purpose.

As to the amount of tremor in the various posi- tions, no difference was detected between pronation and supination. In the midway position less tremor is observed.

For these reasons the position of pronation was considered the most favorable for our purpose, and another point whish influenced us in this selection is that this is the position into which the hand most naturally falls when the arm is extended. It is rare that any one, when extending the arm to place the finger in the thimble, holds it in any other position than that of pronation.

The second series of tracings, one hundred and eighty-five in number, were taken from men between the ages of twenty and thirty, who were undergoing a competitive physical examination and were hence presumably as healthy a set of individuals as could well be found. Nearly every form of ordinary occupation and trade was represented, the liberal professions, of course, excepted. 'The tests were made previous to the physical examination, when the men were fresh and in good condition. The position used was pronation, and each hand was tested separately and with eyes both open and closed. Each test lasted thirty seconds.

In the study of these tracings the same classification is used as in the previous series. They too are divided into the two groups of the stable and unstable (stationary and mobile).

In considering the direction of the movement, it is evident that the tracings of Group I. can afford us no information; they have therefore been placed in the table under the heading "stationary."

This group is of interest mainly in reference to the relation between the results obtained with the eyes open and with the eyes closed.

of tracings with the right hand and with the eyes open it is seen that one hundred and forty-one (76.21 per cent.) are in this group, while of those with the same hand while the eyes are closed only twenty-six (14.05 per cent.) belong here. With the left hand and the eyes open one hundred and sixty (86.44 per cent.) belong in this group, but of those taken with the eyes closed but thirty-six (19.45 per cent.).

Hence with the right hand there is a little more and with the left hand a little less than five times the control with the sight than without it. (This of course does not mean to imply that a given tracing with sight is five times more "stable" than a similar tracing when the eyes are closed, but only that five times as many "stationary" tracings are made when the hand is aided by vision as when not thus aided.)

In all the tracings of Group II. the movement assumes a definite direction. and in the table before us the direction of this movement is shown. The table is arranged so as to give the number and percentage of tracings in each direction in each of the four conditions. The conditions of the tracings are noted by the Roman numerals at the beginning of each line: I. right hand with eyes open; II. right hand, eyes closed; III. left hand, eyes open; IV. left hand, eyes closed. The remarks at the top of the columns show the direction. 'Thus, of tracings with the right hand and with the eyes open, in nine the hand moved to the right and in sixteen to the left, in nineteen downwards, in no case upwards. Of those which moved to the right, six moved downwards in addition and three horizontally only. The total in which the general direction of the movement of the hand was downward was thirty-three, upwards was three.

In a very few cases it may be seen that the hand rose, but so small is their number that they are probably due to accidental causes or to an over-estimated effort to prevent the hand from falling. The per- 
centage in which the hand falls is large, especially when the ejes were closed. In the latter case, with the right hand, it is nearly four times as large as when the eyes were open, and with the left hand nearly five times as large.

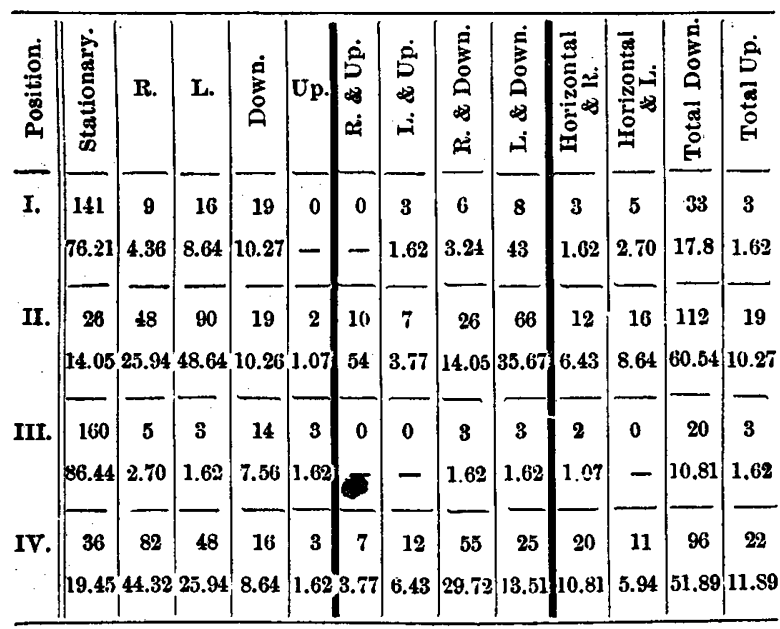

When the lateral direction is considered, a more interesting result is observed, namely, that the tendency of the hand is to move toward the median line of the body, and this is so whether the eyes be open or shut.

The following figures show the number of cases in which the hand moved in each direction:-

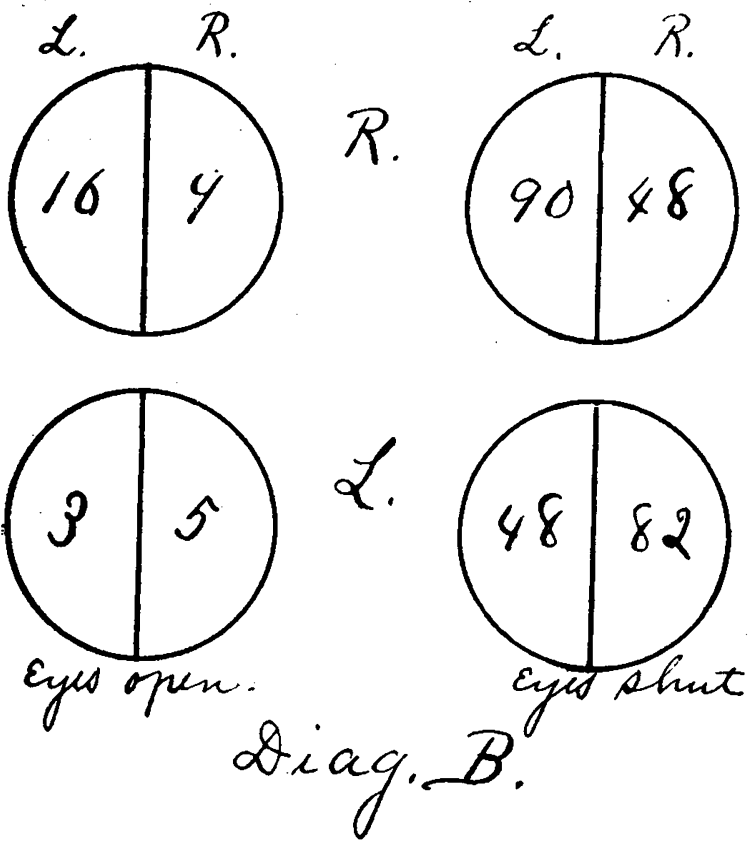

These have reference to the lateral movement only. In a large proportion the direction was obliquely downward, but in a very few it was obliquely upward. With the eyes open only three moved obliquely upward, with the eyes closed thirty-six. When the eyes are closed and the hand is governed only by muscular sense, a large percentage fall toward the middle line of the body, in the proportion of a little more than two to one.

The number of tracings in which the hand moved obliquely upward when the eyes were closed is too small to enable us to form any definite conclusion in this regard, but in the larger number the tendency is to move in the same plane as the majority of those moving downwards, but in an opposite direction.

The figures, Diagram C, express these results diagrammatically, giving in the centre the number of stationary tracings, and in the circumferencs those moving in each oblique direction.

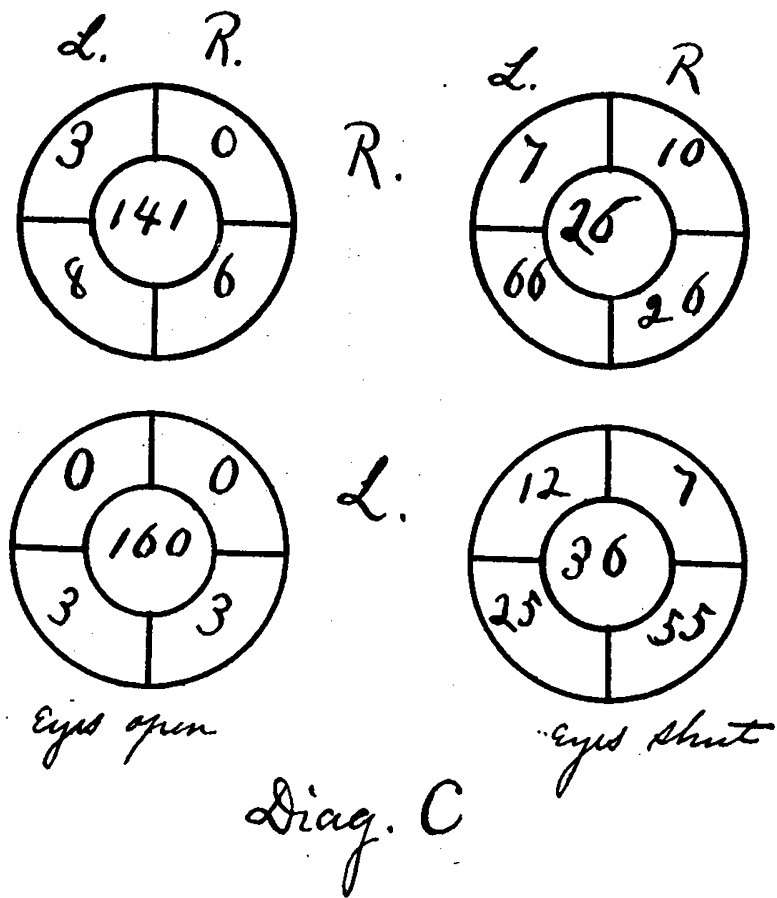

The amount of deviation from the starting point was also considered in order to determine the relative steadiness (stabiiity) under the different conditions. For this purpose the greatest height and width of each tracing was measured.

These measurements were as follows. Averages of Group I. (stable tracings) :-

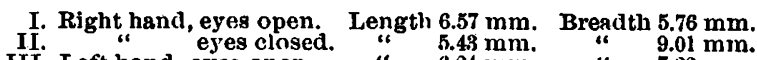
III. Left hand, eyes open.

Group II. The tracings vary considerably in size, as will be seen by comparison of the extremes :-

Position I. Length. Greatest $12.70 \mathrm{~mm}$. Least $2.00 \mathrm{~mm}$. II. Length. “ “ $35.00 \mathrm{~mm}$. “ $20.00 \mathrm{~mm}$. “ $3.75 \mathrm{~mm}$. III. Breadth. “ $\quad 16.20 \mathrm{~mm}$. “ $4.01 \mathrm{~mm}$.

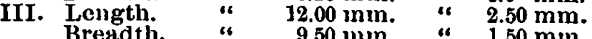

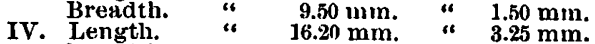
breadth. " $\quad 15.70 \mathrm{~mm}$. " $\quad$ " $1.50 \mathrm{~mm}$.

If we compare now the average measurements of the tracings in both groups according as they were drawn with the eyes open or closed, we find a decided loss of control when the aid of sight is removed.

Averages, Groups I. and II.

Right "sand, eyes open. Length $7.70 \mathrm{~mm}$. Breadth $6.30 \mathrm{~mm}$.

Left hand, eyes open.

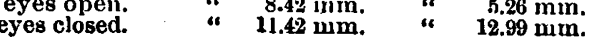

\section{RESUME.}

In a very large proportion of cases with the eyes open the hand is kept approximately in the original position. With the eyes closed this number is 
comparatively small, being about one fifth of the preceding. The average excursion of the hand in these cases, which is a measurement of its steadiness (stability) is $2.37 \mathrm{~mm}$. for the right and 2.00 $\mathrm{mm}$. for the left with the eyes open, and $3.87 \mathrm{~mm}$. for the right and $2.37 \mathrm{~mm}$. for the left with the eyes closed, the steadiness of the left hand being in each case greater than that of the right. The tracings, however, vary very considerably, the extremes being $2 \mathrm{~mm}$. and $20 \mathrm{~mm}$. in the vertical, and $1.50 \mathrm{~mm}$. and $16.20 \mathrm{~mm}$. in the horizontal, planes.

Occupation or training exerts more or less influence on the power to hold the hands in a fixed position (steadily), clerks and those accustomed to use the hands for fine work showing more power in this respect than men accustomed to rough physical work, as laborers, teamsters, etc. A number of records of professional men, not included in those under consideration here, show as a rule much more control than those of any other class examined. The power of control of muscular effort seems to keep pace with mental development. The method of various persons in attempting to control their hands during this test shows this strikingly. Persons accustomed only to rough and unskilled labor are, as a rule, unable to perform the more delicate motions, and are likewise less able to co-ordinate for unusual movements.

The number of tracings in which the hands moved upwards are too few to enable us to draw useful deductions. In the greater number the elevation was but slight, and may have been due to an over-estimated effort to prevent the hand from falling.

When, however, the hand descends a strong tendency to fall towards the median line is observed.

When the hand deviated considerably from the starting point with the eyes shut, the subject had as a rule no knowledge that it had done so, and was much surprised on opening his eyes to discover what had occurred.

As far as could be judged the functional disturbance arising from nervousness had no influence

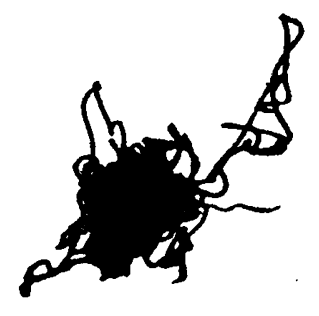

No. 1.

No. 4.

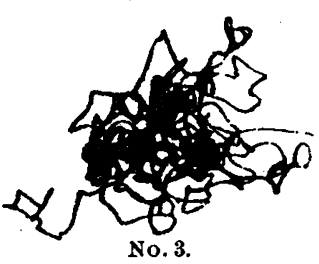

PLATE II.

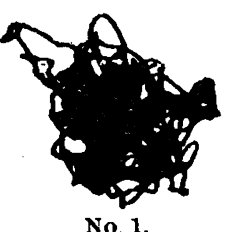

PLATE I.

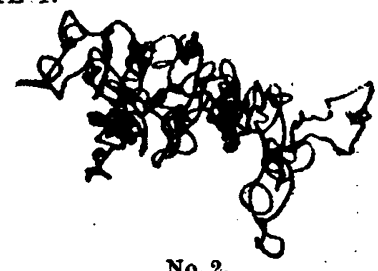

No. 2.

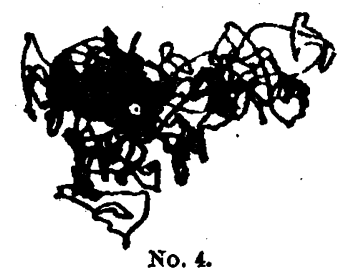

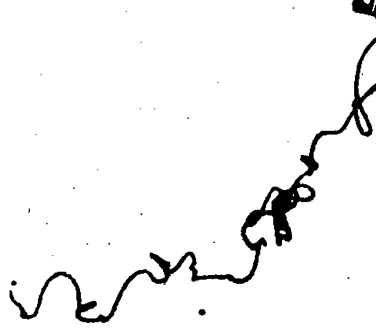

No. 2.

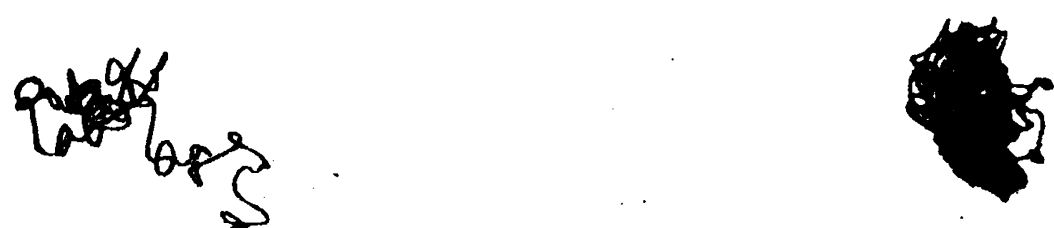

No. 3.

Finger Tracings (natural size).

Figures I. 1, I. 2, I. 3, I. 4, show an ordinary series of finger tracings, all taken from the same Figures I. 1, I. 2, I. 3, I. 4, sliow an ordition person uncer one of the four conditions, 1. closed. This is a typical series of the " regular" typeThere is very litle variation in the extent of the movement under the four conditions. The direc. tion, however, varies: 1 is indeterm!nate, 2 upwards and to the left, 3 and 4 upwards und to the right. Figures II. 1, 2, 3, 4, show anotler series of finger tracings taken in like manner (all frrin one

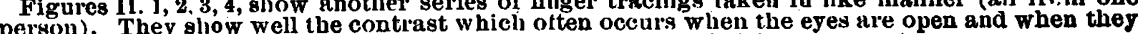
are closed. 1 and 3 eyes open, 2 and 4 eyes closed. Control of vision apparent. 
to increase the deviation from the starting point in any special direction, though it sometimes increased the size of the tracings of Group I. The disturbance from this cause, however, was much less than might at first sight be expected, the unsteadiness in great measure disappearing with the voluntary effort. In two cases, however, the disturbance from this cause was so great that all efforts to comply with the test were futile. With the attempt at muscular fixation the hand was thrown into so severe a spasmodic action that no control was possible. So far as could be determined in these cases no alcoholic influence and no organic disease existed. One of these subjects was a man who passed the physical examination for the police force, the other a woman debilitated by hard work and care.

The tremor can be estimated only by a close study of the tracings. It is totally unconnected with their "stability," or the amount or direction of their deviation. There is probably no tremor registered by this instrument which cannot easily be seen, and the study of its character is complicated by the presence of the coarse movements in the tracing.

Many of the fine tremors are not registered, because the slight support given by the thimble causes them to cease in the finger tested, although the other fingers continue their motion as before.

Hard-working laborers present no special tremor, but hive less "stability" than those accustomed to more delicate work. but such tremor as existed in them was not overcome by mere contact with the instrument.

The emotional tremor is not a fine one. Its amount varies considerably with the individua?, and frequently modifies or obscures any other tremor which may exist. It does not, however, seem to affect the control (stability) of the hand.

HEAD MOVEMENTS. STATIC EQUILIBRIUM.

The observations in regard to static equilibrium were made upon the same individuals as those from whom our second series of hand tracings was taken, that is, on healthy men who were undergoing a competitive physical examination, and whose ages were all, according to their declaration, between twenty and thirty, though it is probable that a few may have been somewhat above the specified age. The total number examined was one hundred and eighty-one, and they were all tested in regard to their relative steadiness in the upright position, with the eyes open and with the eyes shut.

The method of examination was as follows. The men were made to stand with their heels together in military attitude, and with the eyes fixed on some object at a distance, yet easily seen. The apparatus used consisted of a square piece of board held in position on the head by plates of spring brass, and in appearance much like the cap of an Oxford student. On the upper surface of this board a paper was placed to receive the tracing. A horizontal rod was so arranged that it could be adjusted at the desired height, and to this a pen was secured by a hinge joint, which allowed a vertical motion only. In each case the time allowed was thirty seconds, and the pen was not allowed to touch the paper until a moment after the subject had taken the required position. The observation was first taken with the eyes open, and then, after an interval, repeated with the eyes closed.

From these experiments we obtained the following results. No person stood absolutely still during the time of the trial, but some moved much less than others.

The direction of movement was as follows. With the eyes open one hundred and thirty-eight moved forward, and only thirty-five backward, - the remaining eight either moving laterally only, or the direction of movement being indeterminate. With the eyes shut one hundred and ten moved forward and fifty-eight backward, while in eleven the movement was either lateral only or indeterminate, or equally forward and backward. These figures show that the ordinary man; while standing unsupported, has a strong tendency to move the head forward slightly, and this seems to be more free to show itself when the eyes are open, and the person can perceive that he is not actually in danger of losing his balance, than with the eyes shut, when a stronger exertion may be made to keep upright.

In regard to lateral motion, we find that with the eyes open eighty-five moved to the right, and eighty-six to the left, showing no preference for either direction. With the eyes shut, however, ninety-seven moved to the right, and seventy-eight to the left, showing a slight preponderance in favor of the former. Those not counted moved either nearly straight forward or backward, or the direction of their motion could not be determined.

In most of the cases, however, as may be seen from the above, the motion was not simply an anteroposterior or a lateral one, but a combination of the two. Thus with the eyes open sixty-five moved f.rward and to the right, sixty-six forward and to the left, s $x$ ieen backward and to the right, eighteen bac'sward and to the left. With the eyes shut, sixty-two moved forward and to the right, fortysix forward and to the left, twenty-six backward and to the right, twenty-nime backward and to the left (diagram). These figures show again the

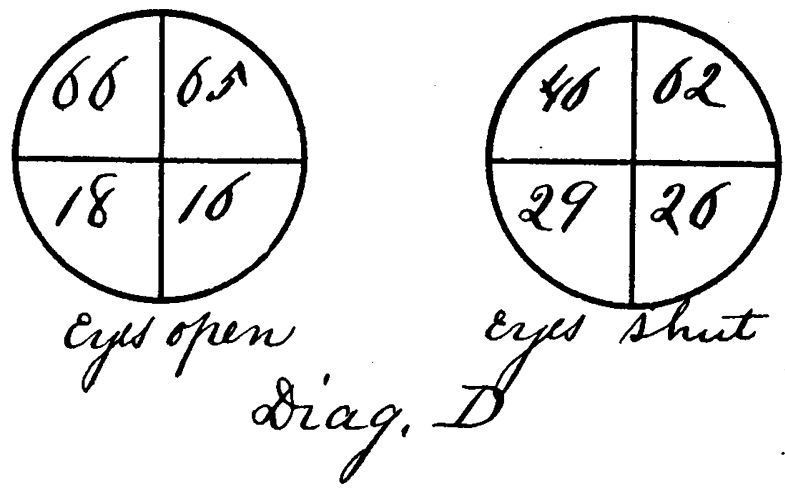

strong tendency to move forward in each case, rather than backward. They show also that this is less marked with the eyes shut than with the eyes open. With the eyes open, for those moving forward there is no preference shown for one side over the other, but with the eyes shut decidedly more move forward and to the right than forward and to the left. When moving backwards, a slight preference is shown, both with the eyes open and 
shut, for the left rather than the right. With the eyes shut there certainly appears to be a decided tendency to move either forward and to the right, or in the reverse direction, backward and to the left, rather than in the other diagonal,-ninety-one (55.8 per cent.) moving in the one diagonal and only seventy-two (44.2 per cent.) in the other.

The foregoing figures show only the general directions of movement, but a number of measurements were also made to determine the position of the person at the end of the trial in relation to his position at, the beginning. It was quite obvious, from an examination of the tracings, that the position at the end of the trial was not by any means always that furthest removed from the position at starting, but that, on the contrary, the subjects moved first in one direction, and then frequently backwards towards or even beyond the starting point,- these movements being, moreover, not always regular, but irregular, or more or less zigzag.

The directions of the points of ending from the starting points were measured on the tracings in degrees and minutes by means of a projector, and the following were the results obtained.

In only a certain proportion of cases could the two points be determined with sufficient accuracy to admit measurement of their relative direction. The direction was always measured from the starting point, which in all cases had been marked, to the point of ending. It was stated, as before noted, in degrees and minutes, - the line of the board pressed on the paper being taken as the base line. Thus any line parallel to this ran from $0^{\circ}$ to $180^{\circ}$, and its perpendicular from $90^{\circ}$ to $270^{\circ}$.

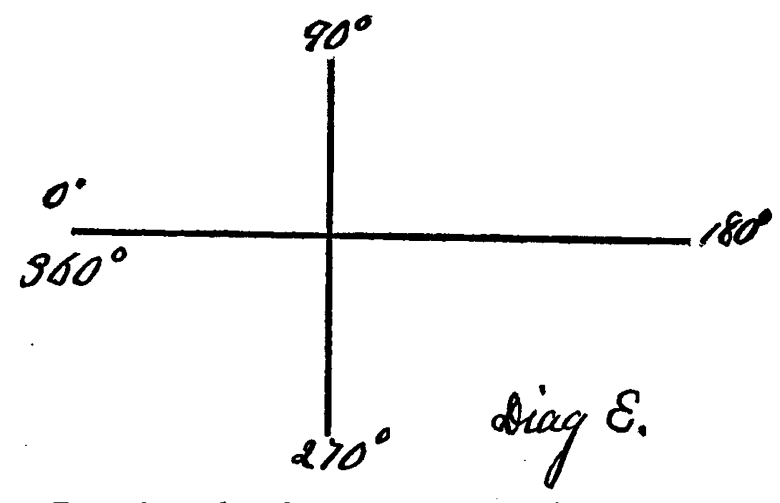

But of one hundred and twenty-five cases with the eyes open, in which these directions could be accurately determined, we found that in forty (32 per cent.) the ending point was upward and to the left of the starting point, since the position of the head at the end of the test was forward and to the right of that at the beginning. In seventy cases (56 per cent.) the position of the head at the end of the time was forward and to the left. In only eleven cases ( 8.8 per cent) was it backward and to the left, and in only four cases (3.2 per cent.) backward and to the right.

From the same number of cases, with the eyes shut, we found that in forty-one (32.8 per cent.) the position of the head at the end of the time was forward and to the right of its position in the beginning. In fifty-three cases (42.4 per cent.) it was forward and to the left of its original position, while in eighteen cases (14.4 per cent.) it was backward and to the left, and in thirteen cases $(\mathbf{1 0 . 4}$ per cent.) it was backward and to the right.

\section{Position of Atead.}
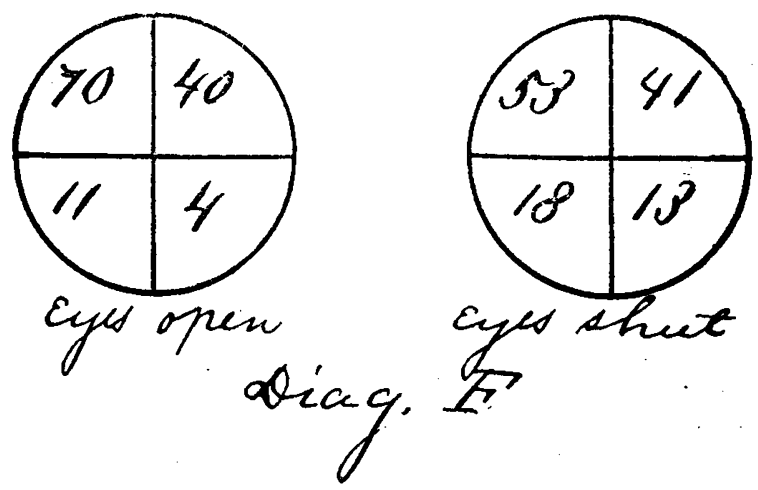

From these figures we see that at the end of a certain period (thirty seconds) in the normal man, standing upright and striving consciously or unconsciously to maintain a stable equilibrium, the tendency is that the head should be in front of its original position, and rather to the left than to the right. Moreover, we see here, as in our previous results, the greater backward tendency with the eyes shut than with the eyes open, 24.8 per cent. of the former to 12 per cent. of the latter, or more than twice as many of those with their eyes shut, having had their heads back of the original position at the end of the half-minute, than of those with their eyes open.

The second question considered in these observar tions was the amount of movement. As the actual length of the lines could not readily be measured, this was determined by measuring the space covered by the lines. Thus the distance from the lowest point directly upwards to a point situated on the same horizontal line as the highest point, was considered as the absolute length. In other words, the distance between two straight parallel horizontal lines, the one passing through the lowest, and the other through the highest point, was considered the length; and similarly the distance between two straight parallel vertical lines drawn through the extreme points on each side was considered the breadth. All measurements were estimated in centimetres.

The measurements were calculated from one hundred and fifty cases as they came in direct order.

The average length with the eyes open was $3.764 \mathrm{~cm}$., the greatest length in any one case $9.2 \mathrm{~cm}$., the least $0.8 \mathrm{~cm}$.

The average length with the eyes closed was $3.475 \mathrm{~cm}$., the greatest length $8.9 \mathrm{~cm}$., the least $1.2 \mathrm{~cm}$.

The average breadth with the eyes open was $1.951 \mathrm{~cm}$., the greatest in any case was $5.4 \mathrm{~cm}$., the least $0.6 \mathrm{~cm}$. (three cases).

The average breadth with the eyes closed was $1.963 \mathrm{~cm}$., the greatest $6.8 \mathrm{~cm}$., the least $0.4 \mathrm{~cm}$.

From these results we can draw several conclusions. In the first place it is evident, as indeed is 
very apparent from the tracings, that the anteroposterior movement is, both with the eyes open and shut, much more extensive as a rule than the lateral movement. Secondly, that the antero-posterior movement is on the average decidedly great $r$ with the eyes open than with the eyes shut, while the lateral movement is the same under both conditions, buing if anything more marked when the eyes ari closed.

In order to show the amount of variation, a calculation was made of the number of cases which were within the limits of each centimetre.

In the following table, in the column under zero, is found the number of cases which measured less than one centimetre; in the column healled one, those measuring between one and two centimetres, and so on.

Table showing amount of variation in anteroposterior movement with the eyes open :-

\begin{tabular}{l|c|c|c|c|c|c|c|c|c}
\hline 0 & 1 & 2 & 3 & 4 & 5 & 6 & 7 & 8 & 9 \\
\hline 1 & 20 & 37 & 48 & 25 & 11 & 9 & 6 & 2 & 1 \\
\hline
\end{tabular}

This table reads: in one case only the length measured less than one centimetre; in twenty cases between one and two centimetres; in thirty-seven between two and three centimetres, and so on.

Measurements were also made to determine the distance between the starting point and the point of ending in each case, which shows the amount of variation in the position of the head at the moment of ending from that at the beginning. The average in one hundred and twenty-five cases with the eyes open was 2.840 centimetres; the greatest distance was 7.7 centimetres; the least was 0.2 (two cases). In the same number of cases with the eyes closed the average was 2.716 centimetres, the greatest distance was 8.0 centimetres, the least was 0.3 centimetres (two cases).

\section{CONCLUSIONS.}

I. The ordinary healthy man, when standing erect unsupported, has a tendency to move forward slightly, and this tendency seems to be more marked when the eyes are open.

II. Those in whom there is a forward movement with the eyes open show no preference in regard to the direction of the lateral movement combined with it, the number moving forward and to the right, and the number moving forward and to the left being nearly equal: When the eyes are closed, however, there is a stronger tendency to move forward and to the right than forward and to the left. Moreover, more persons with the eyes closed moved backward and to the left than backward and to the right.

III. The position of the head at the end of half a minute was found in a large majority of cases to be in front of the position at starting, and a larger number were forward and to the left than forward and to the right. This applies both when the eyes were open and when they were closed.

IV. More than twice as many persons, when their eyes were closed, had their heads back of the original position as did with their eyes open.

$V$. The extent of the antero-posterior movement was somewhat greater with the eyes open than with the eyes closed. The extent of the lateral movement was practically the same under the two conditions.

VI. The average extent of the antero-posterior movement was much greater than that of the lateral movement. In the majority of persons there was but little individual variation in the extent of the movements.

VII. The average distance of the head at the end of the time from its position in the beginning was about 2.8 centimetres with the eyes open, and 2.7 centimetres with the eyes closed.

We cannot conclude this paper without drawing att $n$ ntion to the very interesting article of I)r. Hinsdale on this sulject in The Americun Journal of Medical Sciences for 1878, where the first reported observations on these head movements are detailed.

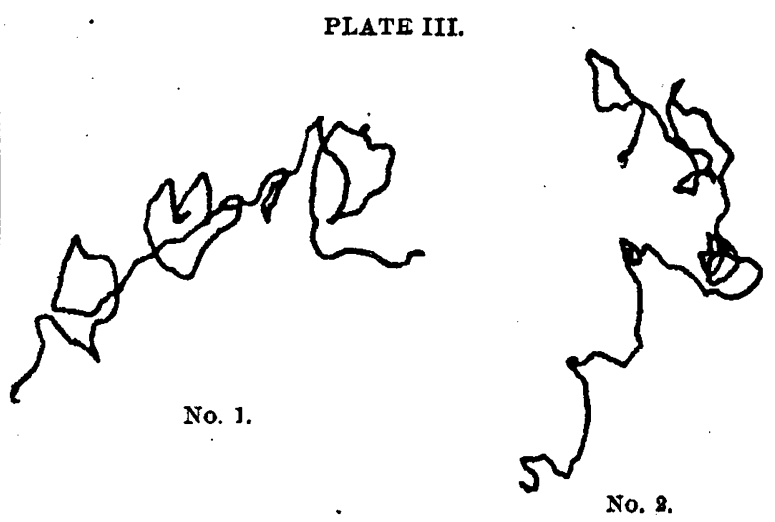

PLATE IV.

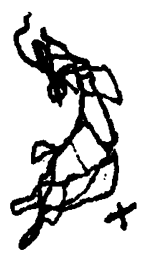

No. 1.
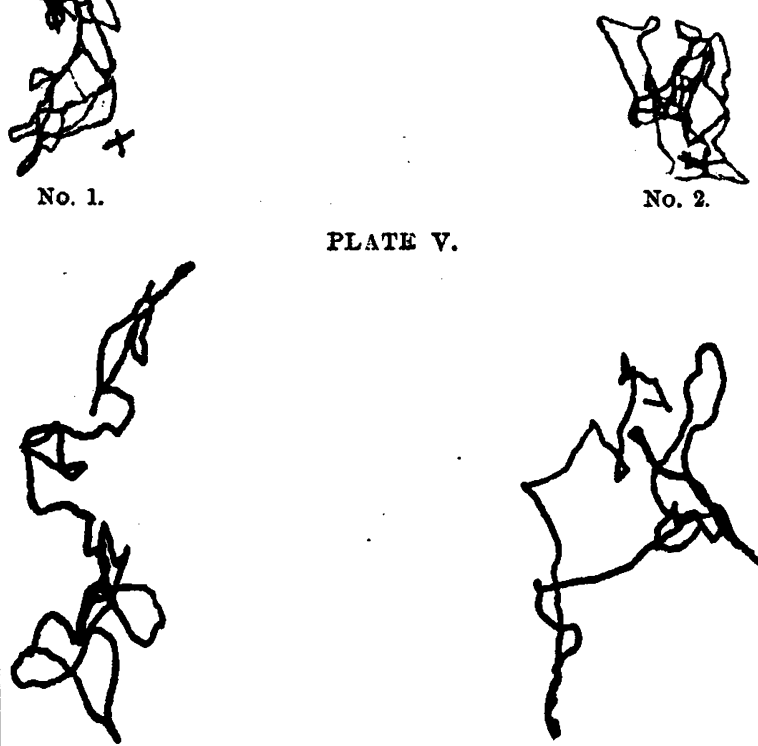

PLATH V.

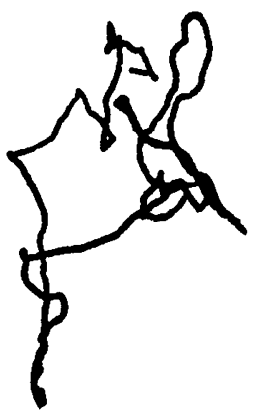

No. 2.

Head Tracings (natural size).

In eacl case the tracings are taken from a single individual with the eyes open (2), anil with the eyes closed (1). In yll cases hey are normal tracings.

1II. These are typical tracings, rather mobile. The direction of movement is rather uncommon, being in both back ward and to the left.

IV. Typis:al tracings, rather stable; direction of motion forward and to the left.

V. Typical tracings, average movement; direction forward and to the right. 
We desire to express our special thanks to our friend, Dr. McCollom, to whose kindness we are indebted for the opportunity of making many of our observations, and also to Dr. Rufus A. Kingman, to whose skill we owe the excellent photograph of the tremograph.

\section{REPORT ON DISEASES OF CHILDREN.' \\ BY T. M. RoTch, M. D.}

THE CEREBRAL PALSIES OF CHILDREN. 8

Oster has reviewed the clinical material at the Philadelphia Infirmary for Nervous Diseases and at the Pennsylvania Institution for Feeble-minded Children at Elwyn. Three divisions are made: hemiplegia, one hundred and twenty cases ; bilateral hemiplegia, nineteen cases; and paraplegia, eleven cases.

Hemiplegia is a common affection in children, according to some writers occurring as frequently as spinal paralysis, but at the Philadelphia Infirmary for Nervous Diseases the proportion is not quite one to four. Of the one hundred and twenty cases, five were boys and sixty-three girls. There was right hemiplegia in sixty-eight and left in fiftytwo cases. Of one hundred and ten cases at which the age at the onset was noted, fifteen were congenital, and in eighty-one the disease came on within the first three years of life. In nine cases the children were delivered with forceps; three were due to trauma; sixteen followed the infectious diseases. In the majority of cases the disease begins with convulsions and the hemiplegia is noticed when the child recovers consciousness. Incomplete recovery is the rule, but the pationts are liable to the serious sequences of epilepsy and mental disorders. Thirtyone cases presented post-hemiplegic movements. The result of an analysis of ninety autopsies is given. In sixteen instances there were vascular lesions, as plugging of a sylvian artery in seven, and hemorrhage in nine.

The age of onset in this group was high, as, excluding three congenital cases, there was only one under three years of age. Atrophy and sclerosis were met with in tifty cases. Two instances are recorded of sclerosis from the Elwyn Institution.

Bilateral spastic hemiplegia is characterized by a spastic condition dating from, or shortly succeeding birth. 'There is no wasting; the reflexes are increased, the mental condition profoundly disturbed and ataxic, and athetoid movements of the most exagserated kind my occur. Nineteen cases are described; two of bilateral athetosis. In sixteen report $d$ autopsies the condition has been either cortic tl sclerosis or porencephalus.

Spastic paraplegiu in children is closely related to bilateral hemiplegia, but the arms are not affected. It dates from birth, or comes on within the first years of life. 'The legs are stiff, the heels raised, and there is strong alliuctor spasm. The patient walks on the toes or there is cross-legred progression. The intellect is not so profoundly impaired as in bilateral hemiplegia. Eleven cases are described.

The morbid anatomy of the affection is not yet

Continued from page 57.5.

3 Ned. News, July 14,21, and 28, A ug. 4 and 11, 1888; $\Lambda$ mer. Jour. Med. Sciences, Nov., 1888 clear. Only one autopsy (by Förster, from the Dresden Children's Hospital) is reported. Cerebial lesion with descending degeneration was present. The reasons are given for believing that it is of cerebral origin, as suggested by Heine many years ago, when he named the disease "paraplegia cerebralis spastica." In the discussion on the pathology of the cerebral palsies, apoplexia neonotorum is held to play an important part in the production of bilateral hemiplegia and paraplegia. In hemiplegia there is still much doubt as to the nature of the initial lesion. Strümpell's poliencephalitis has not yet been demonstrated anatomically, though the view is very plausible, and subsequent autopsies may show the truth of it. The relation of the cases to the infectious cliseases may be due to embolic processes associated with endocarditis, to arteritis or periarteritis such as has been described in the heart in typhoid fever, or to changes in the cerebral gray matter, similar to those which have been described in the cord in measles by Barlow.

The conclusion is reached that infantile hemiplegia is the result of a variety of different processes, of which the most important are :-

(1) Hemorrhage, occurring during violent convulsions, or during paroxysm of whooping-cough.

(2) Post-febrile processes: (a) embolic; (b) endoand peri-arterial changes ; $(c)$ encephalitis.

(3) Thrombosis of the cerebral veins.

Under the section on treatment the question of operative interference is discussed, and two cases are noted in which trephining was performed for Jacksonian epilepsy following infantile hemiplegia. These are held not to be suitable cases for operation.

\section{ACETONURIA.4}

Baginsky has demonstrated the presence of acetone in the urine of healthy children. thus showing the existence of a physiological acetonuria for children, as has already been done for adults. $\mathrm{He}$ found that, pathologically, acetonuria stands in the closest relationship to the duration and intensity of the pyrexial condition; and experimentally, too, he found that in dors acetonuria is intimately connected with protein waste.

THE INFLUENCE OF BACTERIA UPON THE DIGISTION OF CHILDREN. 5

Baginsky, in a paper before the Berlin Medical Society, stitas that the bacterium of the lastic fermentation causes the produstion of acet:c asid and acetone, as well as lactic acid. 'This formation goes on without oxygen, and is not hindered by the bile.

'The neutral lactates are changed to butyric acid; starch is not changed to strgar, nor is casein or albumin decomposed. The gases formed when acetic acil is proluced are carbonic acid, hydrog $3 n$, and inethane.

He proposes to name this bacterium the "acetic bacteriun." He further found that this ba trium is destroyed by acetic acid.

In examining the stools of children suffering from cholera infantum, he isolated a bacterium which produced green stools (the germ of Hayem

4 Archiv f. Heilkuncle. vol. ix.; Amer. Jour. Mell. Sciences, A pril, Sis.

5 Berlin. Kliniwch. Wochensch., No. 26, 1883; $\Lambda$ mer. Jour. Mfeil Sciences, Oct., $18>8$. 